\title{
Prediction of Respiratory Outcome in Extremely Low Gestational Age Infants
}

\author{
Richard B. Parad ${ }^{\text {a Jonathan M. Davis }}{ }^{b}$ Jessica Lo ${ }^{c, d}$ Mark Thomas ${ }^{\text {e }}$ \\ Neil Marlow ${ }^{f}$ Sandy Calvert ${ }^{g}$ Janet L. Peacock ${ }^{c, d} \quad$ Anne Greenough $^{d, h}$ \\ ${ }^{a}$ Department of Pediatric Newborn Medicine, Brigham and Women's Hospital, and bepartment of Pediatrics, \\ Floating Hospital for Children at Tufts Medical Center, Boston, Mass., USA; ' Division of Health and Social Care \\ Research, King's College London, dNIHR Biomedical Research Centre at Guy's and St. Thomas' NHS Foundation Trust \\ and King's College London, ${ }^{\mathrm{e}}$ Neonatal Medicine, Chelsea and Westminster Hospital, ${ }^{\mathrm{f}}$ Neonatal Medicine, Institute \\ for Women's Health, ${ }^{9}$ Child Health, St. George's Hospital, and h'Division of Asthma, Allergy and Lung Biology, King's \\ College London, London, UK
}

\section{Key Words}

Bronchopulmonary dysplasia $\cdot$ Pulmonary function .

Premature infant $\cdot$ Respiratory outcome

\begin{abstract}
Background: Bronchopulmonary dysplasia (BPD) is a commonly used outcome for randomized neonatal trials. Objectives: The aim of the present study was to determine whether a diagnosis of BPD or respiratory morbidity $\left(\mathrm{RM}_{1}\right.$ or $\left.\mathrm{RM}_{2}\right)$ at 12 months corrected age better predicted subsequent RM in extremely low gestational age infants (23-28 weeks of gestation). Methods: Initial analysis was undertaken in a development cohort of 76 infants who underwent pulmonary function tests (PFTs) at 12 months corrected age. Parents completed infant respiratory diaries 2 weeks before the PFTs. Analysis was then undertaken in a validation cohort of 227 infants whose parents completed a 4-week respiratory diary when their infant was 12 months corrected age. BPD at 28 days $\left(\mathrm{BPD}_{28 \mathrm{~d}}\right)$ and 36 weeks post-menstrual age $\left(\mathrm{BPD}_{36 \mathrm{w}}\right)$, $\mathrm{RM}_{1}$ ( $\geq 3$ days and/or nights of cough, wheeze, and/or medicine use) and $\mathrm{RM}_{2}$ ( $\geq 4$ days and/or nights of cough, wheeze,
\end{abstract}

and/or respiratory medicine use) each week for 2 weeks at 12 months corrected age were assessed with regard to prediction of respiratory outcomes at 24 months documented by respiratory health questionnaires. Results: $\mathrm{BPD}_{28 \mathrm{~d}}$ and $\mathrm{BPD}_{36 \mathrm{w}}$ were not significantly associated with any respiratory outcome. Areas under the receiver operating characteristic curves were significantly better for either definition of $\mathrm{RM}$ than $\mathrm{BPD}_{28 \mathrm{~d}}$ or $\mathrm{BPD}_{36 \mathrm{w}}$ for all outcomes. Conclusions: $\mathrm{RM}$ documented by parental completed diaries at 12 months corrected age better predicted respiratory outcome at 24 months corrected age than BPD regardless of diagnostic criteria.

(c) 2015 S. Karger AG, Basel

\section{Introduction}

Infants born at extremely low gestational ages frequently develop bronchopulmonary dysplasia (BPD) and chronic respiratory morbidity (RM) [1]. Chronic RM is important as it increases health-care utilization and the related health-care costs, as well as adversely impacting

\section{KARGER 125\%}

(c) 2015 S. Karger AG, Basel

1661-7800/15/1074-0241\$39.50/0

E-Mail karger@karger.com

www.karger.com/neo
Anne Greenough

NICU, 4th Floor, Golden Jubilee Wing

King's College Hospital, Denmark Hill

London SE5 9RS (UK)

E-Mail anne.greenough@kcl.ac.uk 
on the lives of affected children and their families. Thus, it is essential to determine how chronic RM is best predicted and hence appropriate interventions be most effectively targeted. The incidence of survival without BPD is a commonly used primary outcome in clinical trials, although a diagnosis of BPD may, however, correlate poorly with RM in the first years after birth. For example, Tyson et al. [2] studied 807 infants randomised to placebo or vitamin A and found a small, but significant, reduction in the incidence of BPD in infants receiving vitamin A. Yet, a follow-up study when the infants were 1 year corrected age revealed no benefits in longer-term pulmonary outcome [3]. In contrast, in a randomised trial, recombinant human superoxide dismutase (rhSOD) was not associated with a reduction in the combined outcome of death or BPD at 36 weeks post-menstrual age (PMA). A follow-up study, however, demonstrated significant reductions in episodes of respiratory illness severe enough to require the use of respiratory medications at 12 months corrected age and reductions in hospital admissions and emergency room visits in the highest-risk infants who received rhSOD [4].

Parent-completed diary cards, to assess respiratory status and RM at follow-up, have been developed for prematurely born infants $[5,6]$. The aim of this study was to determine whether RM as recorded by parental completed diary cards at 1 year corrected age was a better predictor of subsequent RM at follow-up, that is at 2 years of age, than a diagnosis of BPD, whether defined as oxygen dependency at 28 days after birth $\left(\mathrm{BPD}_{28 \mathrm{~d}}\right)$ or 36 weeks PMA (BPD $\left.{ }_{36 \mathrm{w}}\right)$.

\section{Methods}

\section{Study Population}

The subjects were part of the United Kingdom Oscillation Study (UKOS) [7]. Infants born between 23 and 28 weeks gestational age entered into UKOS were randomised to high-frequency oscillation or conventional mechanical ventilation within $1 \mathrm{~h}$ of birth. There were no statistically significant differences between the two groups in short-term pulmonary outcomes, pulmonary function results at 1 year [8], or RM up to 24 months corrected age [9], hence the results were pooled for this study. The South Thames Multicentre Research Ethics Committee and the local research ethics committee at each participating centre approved the study.

Initial analysis in this study was undertaken in a development cohort which included a subset of 76 infants who participated in detailed pulmonary function assessments at 12 months corrected age (pulmonary function subset) [8]. Subsequent analysis was undertaken in a validation cohort of 227 UKOS infants whose parents completed a 4-week diary card when their infant was 12 months corrected age (fig. 1).

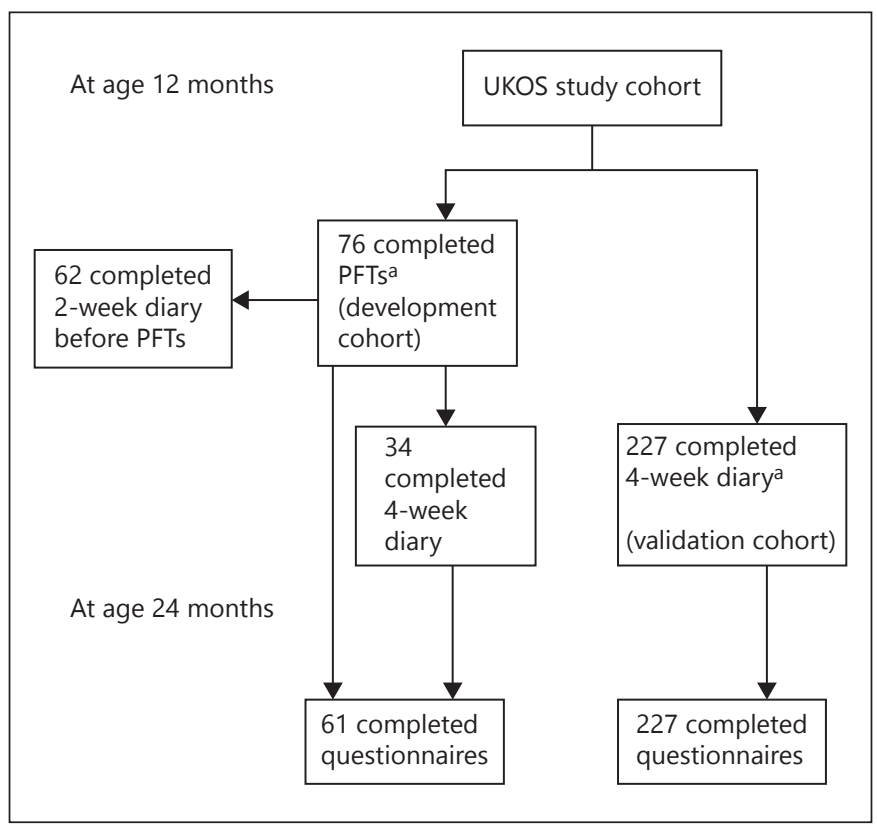

Fig. 1. Flow diagram of the cohorts. ${ }^{a}$ There were 29 infants included in both cohorts.

\section{Diary Card and Respiratory Questionnaire}

Prior to the pulmonary function tests (PFTs), parents were asked to complete a 2-week infant respiratory diary card to assess whether or not their infant was too symptomatic to undergo sedation for pulmonary function testing. Parents recorded daily (both day and night) whether their child had coughed, wheezed, and/or had taken respiratory medication (inhaled bronchodilators and/or inhaled/systemic corticosteroids).

Paediatricians completed a respiratory questionnaire with parents when their infant was 24 months corrected age during routine follow-up visits. The questionnaires recorded parental reports of whether the child had suffered from cough or wheeze, taken any medication to control or prevent respiratory symptoms, or had been admitted to the hospital for respiratory illnesses (all were analysed as yes/no).

\section{Analysis}

The definition of RM $\left(\mathrm{RM}_{1}\right)$ was determined a priori as being at least 3 days per week of the child having cough, wheeze, and/or use of respiratory medicines (all recorded as yes/no), each week during the 2-week pre-PFT period $\left(\mathrm{RM}_{1}\right)$. This definition was chosen as it was felt likely to reflect ongoing RM rather than shortlasting symptoms associated with an acute respiratory tract infection. A sensitivity analysis was then performed using at least 4 days and/or nights of cough, wheeze, and/or use of respiratory medicines each week for the 2-week pre-PFT period $\left(\mathrm{RM}_{2}\right)$. For the initial analysis, data from the 2-week diary were used $(n=62$ were completed).

The association of $\mathrm{BPD}_{28 \mathrm{~d}}$ and $\mathrm{BPD}_{36 \mathrm{w}}$ with the respiratory outcomes at 24 months corrected age were examined. The area under the receiver operating characteristic (ROC) curve was calculated to compare the strength of association between variables. 
Table 1. Demographics of the infants who underwent pulmonary function testing (development cohort) and of the infants whose parents completed the 4-week diary card (validation cohort)

\begin{tabular}{lcc}
\hline & Development cohort & Validation cohort \\
\hline Infants & 76 & 227 \\
Male & $42(55)$ & $113(50)$ \\
Gestational age, week & $26(23-28)$ & $27(23-28)$ \\
Birth weight, g & $870(458-1,335)$ & $890(500-1,459)$ \\
Birth weight z-score & $-0.47(-3.45$ to 1.73$)$ & $-0.46(-3.30$ to 2.41$)$ \\
Small for gestational age (birth weight z-score $<-1.28)$ & $13(17)$ & $53(23)$ \\
Multiple birth & $16(21)$ & $59(26)$ \\
Race & & \\
$\quad$ White & $56(74)$ & $208(92)$ \\
$\quad$ Black & $13(17)$ & $8(4)$ \\
$\quad$ Other & $7(9)$ & $11(5)$ \\
Maternal smoking in pregnancy & $13(20)$ & $46(20)$ \\
Oxygen dependent at 28 days & $64(84)$ & $190(84)$ \\
Oxygen dependent at 36 weeks PMA & $45(59)$ & $142(63)$ \\
Oxygen dependent at discharge & $14(18)$ & $50(22)$ \\
Days on ventilator support & $14(0-112)$ & $8(0-62)$ \\
Air leak & $11(14)$ & $28(12)$ \\
\hline
\end{tabular}

The data are presented as median (range) or $\mathrm{n}(\%)$.

The associations between respiratory outcomes and $\mathrm{RM}_{1}$ and $\mathrm{RM}_{2}$ were then examined. The strength of associations of $\mathrm{BPD}_{28 \mathrm{~d}}$, $\mathrm{BPD}_{36 \mathrm{w}}, \mathrm{RM}_{1}$, and $\mathrm{RM}_{2}$ with respiratory outcomes at 24 months corrected age were compared using the test of equality of ROC areas [10].

A further validation cohort of 34 infants who underwent pulmonary function testing and whose parents completed 4-week diary cards was used to validate the definitions of $\mathrm{RM}_{1}$ and $\mathrm{RM}_{2}$. The sensitivity and specificity, positive and negative predictive values of $\mathrm{RM}_{1}$ and $\mathrm{RM}_{2}$ for respiratory outcomes at 24 months corrected age were then calculated using the prior definition and the sensitivity definition described above. A further sensitivity analysis was performed to assess the predictive ability of $\mathrm{RM}_{1}$ and $\mathrm{RM}_{2}$ but using the 227 UKOS infants whose parents completed the 4-week diary cards at 12 months corrected age. All analyses were performed using Stata v12.1.

\section{Results}

Eighty-four percent of the 76 infants in the development cohort were oxygen dependent at 28 days after birth $\left(\mathrm{BPD}_{28 \mathrm{~d}}\right)$ and $59 \%$ were oxygen dependent at 36 weeks PMA ( $\mathrm{BPD}_{36 \mathrm{w}}$ ) (table 1). The demographics of the 227 infants in the validation cohort whose results were included in the subsequent analysis were similar (table 1).

In the development cohort, neither $\mathrm{BPD}_{28 \mathrm{~d}}$ nor $\mathrm{BP}$ $\mathrm{D}_{36 \mathrm{w}}$ were significantly related to any respiratory outcome (table 2). In the validation cohort whose parents completed the 4-week diary cards, there was no evidence that either definition of BPD was related to any of the respiratory outcomes at 24 months corrected age (table 2). All respiratory outcomes at 24 months corrected age (except hospital admissions) were significantly related to both $\mathrm{RM}_{1}$ and $\mathrm{RM}_{2}$ (table 3 ).

The areas under the ROC curves were higher for all respiratory outcomes using either $\mathrm{RM}_{1}$ and $\mathrm{RM}_{2}$ as compared to either $\mathrm{BPD}_{28 \mathrm{~d}}$ or $\mathrm{BPD}_{36 \mathrm{w}}$ (table 4). $\mathrm{RM}_{1}$ and $\mathrm{RM}_{2}$ compared to either $\mathrm{BPD}_{28 \mathrm{~d}}$ or $\mathrm{BPD}_{36 \mathrm{w}}$ were statistically significantly more predictive of later outcomes, as judged by comparing the ROC curves, for the combined outcome of cough, wheeze, and/or use of respiratory medicines for $\mathrm{RM}_{1}$ compared to $\mathrm{BPD}_{28 \mathrm{~d}}$ and for cough for $\mathrm{RM}_{1}$ compared to $\mathrm{BPD}_{36 \mathrm{w}}$ (table 4). Similar patterns were observed for $\mathrm{RM}_{2}$. In the sensitivity analysis using the larger cohort $(\mathrm{n}=227)$, all respiratory outcomes at 24 months were better predicted by $\mathrm{RM}_{1}$ and $\mathrm{RM}_{2}$ than $\mathrm{BPD}_{28 \mathrm{~d}}$ and $\mathrm{BPD}_{36 \mathrm{w}}$.

Analysis of the 4-week diary card data demonstrated that $\mathrm{RM}_{1}$ and $\mathrm{RM}_{2}$ significantly predicted cough, wheeze, and/or use of respiratory medications documented by the 24-month corrected age questionnaire (table 5).

$\mathrm{RM}_{1}$ and $\mathrm{RM}_{2}$ had specificities ranging from 58 to $91 \%$ and sensitivities ranging from 64 to $81 \%$ for the different follow-up respiratory outcomes at 24 months corrected age in the development cohort. Positive and negative predictive values ranged from 42 to $86 \%$ and from 67 to $85 \%$, 
Table 2. Association of BPD defined as either oxygen dependency at 28 days or at 36 weeks PMA with respiratory outcomes

(a) Analysis using data from the development cohort $(n=76)$

(1) Oxygen dependency at 28 days $\left(\mathrm{BPD}_{28 \mathrm{~d}}\right)$

Respiratory hospital admission

Cough

Wheeze

Respiratory medications (all types)

Any cough, wheeze, and/or use of respiratory medications

(2) Oxygen dependency at 36 weeks PMA $\left(\mathrm{BPD}_{36 \mathrm{w}}\right)$

Respiratory hospital admission

Cough

Wheeze

Respiratory medications (all types)

Any cough, wheeze, and/or use of respiratory medications

$\begin{array}{llll}61 & 3.89(0.45,33.6)^{*} & 0.22^{* *} & 0.55 \\ 60 & 2.66(0.50,14.1) & 0.25 & 0.56 \\ 61 & 1.85(0.35,9.86) & 0.47 & 0.54 \\ 60 & 1.52(0.37,6.33) & 0.56 & 0.53 \\ 61 & 1.58(0.38,6.55) & 0.53 & 0.53 \\ & & & \\ 61 & 1.58(0.50,5.00) & 0.43 & 0.55 \\ 60 & 2.43(0.81,7.27) & 0.11 & 0.60 \\ 61 & 2.02(0.65,6.28) & 0.23 & 0.58 \\ 60 & 3.41(1.16,9.98) & 0.025 & 0.65 \\ 61 & 2.65(0.93,7.58) & 0.069 & 0.62\end{array}$

(b) Analysis using data from the validation cohort with 4-week diary card results $(n=227)$

(1) Oxygen dependency at 28 days $\left(\mathrm{BPD}_{28 \mathrm{~d}}\right)$

Respiratory hospital admission

Cough

225

Wheeze

226

$0.94(0.38,2.32)$

0.90

0.50

Respiratory medications (all types)

Any cough, wheeze, and/or use of respiratory medications 227

$1.22(0.60,2.48)$

0.59

0.51

$1.72(0.80,3.71)$

0.17

0.54

$227 \quad 1.56(0.77,3.18)$

0.062

0.55

(2) Oxygen dependency at 36 weeks PMA ( $\left.\mathrm{BPD}_{36 \mathrm{w}}\right)$

Respiratory hospital admission

\section{5}

226

Cough

217

Wheeze

227

Respiratory medications (all types)

227

$1.41(0.69,2.90)$

0.22

0.53

Any cough, wheeze, and/or use of respiratory medications

$1.10(0.64,1.88)$

0.35

0.54

$0.90(0.51,1.56)$

0.73

0.51

$1.55(0.90,2.66)$

0.70

0.51

* The difference is BPD versus no BPD; ** p value from $t$ test.

Table 3. Association of $\mathrm{RM}_{1}$ and $\mathrm{RM}_{2}$ with PFT results and respiratory outcomes at 24 months corrected age

\begin{tabular}{|c|c|c|c|c|c|c|c|}
\hline $\begin{array}{l}\text { Respiratory outcome at } 24 \text { months } \\
\text { corrected age }\end{array}$ & $\mathrm{n}$ & OR $(95 \% \mathrm{CI})$ & $\mathrm{p}$ value & $\begin{array}{l}\text { area under } \\
\text { ROC curve }\end{array}$ & OR $(95 \% \mathrm{CI})$ & $\mathrm{p}$ value & $\begin{array}{l}\text { area under } \\
\text { ROC curve }\end{array}$ \\
\hline
\end{tabular}

(a) Analysis using data from the development cohort $(n=76)$

Respiratory hospital admission

Cough

Wheeze

$523.08(0.88,10.7)$

$51 \quad 11.7(3.01,45.4) \quad<0.001$

0.64

$\begin{array}{llll}52 & 5.50(1.48,20.5) & 0.011 & 0.70\end{array}$

0.12

0.55

Respiratory medications (all types)

$\begin{array}{llll}51 & 7.08(2.05,24.5) & 0.002 & 0.73\end{array}$

0.31

0.53

Any cough, wheeze, and/or use of respiratory medications

$52 \quad 9.45(2.62,34.1) \quad 0.001 \quad 0.75$

$\begin{array}{lrr}5.72(1.58,20.7) & 0.008 & 0.70 \\ 12.5(3.25,48.1) & <0.001 & 0.77 \\ 4.58(1.33,15.8) & 0.016 & 0.68 \\ 12.0(2.85,50.6) & 0.001 & 0.76 \\ & & \\ 20.0(3.87,102.9) & <0.001 & 0.78\end{array}$

(b) Analysis using data from the validation cohort with results from the 4-week diary card $(n=227)$

Respiratory hospital admission

Cough

Wheeze

Respiratory medications (all types)

Any cough, wheeze, and/or use of respiratory medications

\begin{abstract}
225
226

217
\end{abstract}

0.69

0.69

0.69

0.73

$227 \quad 7.00(3.69,13.3)<0.001$

0.72
$3.90(1.92,7.95) \quad<0.001$

$5.54(3.09,9.91)<0.001$

$5.82(3.21,10.6)<0.001$

$10.0(5.06,19.8)<0.001$

$9.95(4.75,20.8) \quad<0.001$

\subsection{6}

0.69

0.70

0.74

0.73 
Table 4. Comparison of ROC areas of $\mathrm{RM}_{1}, \mathrm{RM}_{2}, \mathrm{BPD}_{28 \mathrm{~d}}$, and $\mathrm{BPD}_{36 \mathrm{w}}$ with respiratory outcomes at 24 months corrected age

\begin{tabular}{|c|c|c|c|c|c|c|}
\hline \multirow[t]{2}{*}{ Respiratory outcome at 24 months } & \multirow[t]{2}{*}{$\mathrm{n}$} & \multicolumn{5}{|c|}{ Area under ROC curve } \\
\hline & & $\mathrm{RM}_{1}$ & $\mathrm{BPD}_{28 \mathrm{~d}^{\mathrm{a}}}$ & $\mathrm{p}$ value & $\mathrm{BPD}_{36 w}{ }^{\mathrm{a}}$ & $\mathrm{p}$ value \\
\hline \multicolumn{7}{|l|}{ (a) Analysis using data from the development cohort $(n=76)$} \\
\hline Respiratory hospital admission & 52 & 0.64 & 0.55 & 0.33 & 0.52 & 0.26 \\
\hline Cough & 51 & 0.77 & 0.54 & 0.0008 & 0.57 & 0.027 \\
\hline Wheeze & 52 & 0.70 & 0.51 & 0.015 & 0.54 & 0.086 \\
\hline Respiratory medications (all types) & 51 & 0.73 & 0.49 & 0.0017 & 0.60 & 0.18 \\
\hline \multirow[t]{2}{*}{ Any cough, wheeze, and/or use of respiratory medications } & 52 & 0.75 & 0.50 & 0.0004 & 0.57 & 0.042 \\
\hline & & $\mathrm{RM}_{2}$ & $\mathrm{BPD}_{28 \mathrm{~d}^{\mathrm{a}}}$ & $\mathrm{p}$ value & $\mathrm{BPD}_{36 \mathrm{w}}{ }^{\mathrm{a}}$ & $\mathrm{p}$ value \\
\hline Respiratory hospital admission & 52 & 0.70 & 0.55 & 0.067 & 0.52 & 0.065 \\
\hline Cough & 51 & 0.77 & 0.54 & 0.0008 & 0.57 & 0.030 \\
\hline Wheeze & 52 & 0.68 & 0.51 & 0.036 & 0.54 & 0.16 \\
\hline Respiratory medications (all types) & 51 & 0.76 & 0.49 & 0.0001 & 0.60 & 0.084 \\
\hline \multirow[t]{2}{*}{ Any cough, wheeze, and/or use of respiratory medications } & 52 & 0.78 & 0.50 & $<0.001$ & 0.57 & 0.012 \\
\hline & & $\mathrm{RM}_{1}$ & $\mathrm{BPD}_{28 \mathrm{~d}}$ & $\mathrm{p}$ value & $\mathrm{BPD}_{36 \mathrm{w}}$ & $\mathrm{p}$ value \\
\hline \multicolumn{7}{|c|}{ (b) Analysis using data from the validation cohort with 4-week diary card results $(n=227)$} \\
\hline Respiratory hospital admission & 225 & 0.69 & 0.50 & $<0.001$ & 0.54 & 0.003 \\
\hline Cough & 226 & 0.69 & 0.51 & $<0.001$ & 0.51 & $<0.001$ \\
\hline Wheeze & 217 & 0.69 & 0.54 & $<0.001$ & 0.51 & $<0.001$ \\
\hline Respiratory medications (all types) & 227 & 0.73 & 0.55 & $<0.001$ & 0.55 & $<0.001$ \\
\hline \multirow[t]{2}{*}{ Any cough, wheeze, and/or use of respiratory medications } & 227 & 0.72 & 0.53 & $<0.001$ & 0.53 & $<0.001$ \\
\hline & & $\mathrm{RM}_{2}$ & $\mathrm{BPD}_{28 \mathrm{~d}}$ & $\mathrm{p}$ value & $\mathrm{BPD}_{36 \mathrm{w}}$ & $\mathrm{p}$ value \\
\hline Respiratory hospital admission & 225 & 0.66 & 0.50 & 0.0003 & 0.54 & 0.017 \\
\hline Cough & 226 & 0.69 & 0.51 & $<0.001$ & 0.51 & $<0.001$ \\
\hline Wheeze & 217 & 0.70 & 0.54 & $<0.001$ & 0.51 & $<0.001$ \\
\hline Respiratory medications (all types) & 227 & 0.74 & 0.55 & $<0.001$ & 0.55 & $<0.001$ \\
\hline Any cough, wheeze, and/or use of respiratory medications & 227 & 0.73 & 0.53 & $<0.001$ & 0.53 & $<0.001$ \\
\hline
\end{tabular}

${ }^{a}$ Note that these values are different from table 2 since the group of children included in this analysis is smaller.

Table 5. Validation of $\mathrm{RM}_{1}$ and $\mathrm{RM}_{2}$ data using the 4-week diary card data from the development cohort

\begin{tabular}{|c|c|c|c|c|c|c|c|}
\hline $\begin{array}{l}\text { Respiratory outcome at } \\
24 \text { months corrected age }\end{array}$ & $\mathrm{n}$ & OR $(95 \% \mathrm{CI})$ & $\mathrm{p}$ value & $\begin{array}{l}\text { area under } \\
\text { ROC curve }\end{array}$ & OR $(95 \%$ CI $)$ & $\mathrm{p}$ value & $\begin{array}{l}\text { area under } \\
\text { ROC curve }\end{array}$ \\
\hline Respiratory hospital admission & 29 & $6.50(1.05,40.1)$ & 0.044 & 0.71 & $4.67(0.87,25.1)$ & 0.073 & 0.68 \\
\hline Cough & 29 & $16.3(1.63,163)$ & 0.017 & 0.79 & $9.00(1.35,59.8)$ & 0.023 & 0.75 \\
\hline Wheeze & 29 & $8.67(1.39,53.8)$ & 0.020 & 0.74 & $6.50(1.20,35.6)$ & 0.03 & 0.72 \\
\hline
\end{tabular}


Table 6. Sensitivity, specificity, positive predictive value, and negative predictive value for $\mathrm{RM}_{1}$ and $\mathrm{RM}_{2}$ and the respiratory outcome at 24 months

\begin{tabular}{|c|c|c|c|c|c|c|c|c|}
\hline \multirow[t]{2}{*}{ Respiratory outcome at 24 months } & \multicolumn{4}{|l|}{$\mathrm{RM}_{1}$} & \multicolumn{4}{|l|}{$\mathrm{RM}_{2}$} \\
\hline & sensitivity & specificity & $\begin{array}{l}\text { positive } \\
\text { predictive } \\
\text { value }\end{array}$ & $\begin{array}{l}\text { negative } \\
\text { predictive } \\
\text { value }\end{array}$ & sensitivity & specificity & $\begin{array}{l}\text { positive } \\
\text { predictive } \\
\text { value }\end{array}$ & $\begin{array}{l}\text { negative } \\
\text { predictive } \\
\text { value }\end{array}$ \\
\hline \multicolumn{9}{|c|}{ (a) Analysis using data from the development cohort $(n=76)$} \\
\hline Respiratory hospital admission & $69(41,89)$ & $58(41,75)$ & $42(23,63)$ & $81(61,93)$ & $69(41,89)$ & $72(55,86)$ & $52(30,74)$ & $84(66,95)$ \\
\hline Cough & $81(58,95)$ & $73(54,88)$ & $68(47,85)$ & $85(65,96)$ & $71(48,89)$ & $83(65,94)$ & $75(51,91)$ & $81(63,93)$ \\
\hline Wheeze & $77(50,93)$ & $63(45,79)$ & $50(30,70)$ & $85(65,96)$ & $65(38,86)$ & $71(54,85)$ & $52(30,74)$ & $81(63,93)$ \\
\hline Respiratory medications (all types) & $71(51,87)$ & $74(52,90)$ & $77(56,91)$ & $68(47,85)$ & $64(44,81)$ & $87(66,97)$ & $86(64,97)$ & $67(47,83)$ \\
\hline $\begin{array}{l}\text { Any cough, wheeze, and/or use of } \\
\text { respiratory medications }\end{array}$ & $72(53,87)$ & $78(56,93)$ & $81(61,93)$ & $69(48,86)$ & $66(46,82)$ & $91(72,99)$ & $91(70,99)$ & $68(49,83)$ \\
\hline \multicolumn{9}{|c|}{ (b) Analysis using data from the validation cohort with results from the 4-week diary card $(n=227)$} \\
\hline Respiratory hospital admission & $76(61,88)$ & $61(54,68)$ & $31(22,41)$ & $92(85,96)$ & $67(51,80)$ & $66(59,73)$ & $31(22,42)$ & $90(83,94)$ \\
\hline Cough & $66(57,75)$ & $72(63,80)$ & $68(58,77)$ & $71(62,78)$ & $61(51,70)$ & $78(70,85)$ & $71(61,80)$ & $69(60,77)$ \\
\hline Wheeze & $69(58,78)$ & $70(62,78)$ & $62(51,71)$ & $76(68,84)$ & $64(53,74)$ & $77(68,84)$ & $66(55,75)$ & $75(67,83)$ \\
\hline Respiratory medications (all types) & $66(57,74)$ & $80(71,88)$ & $82(73,89)$ & $64(55,72)$ & $61(52,69)$ & $87(78,93)$ & $86(77,92)$ & $62(54,70)$ \\
\hline $\begin{array}{l}\text { Any cough, wheeze, and/or use of } \\
\text { respiratory medications }\end{array}$ & $62(54,70)$ & $81(71,89)$ & $85(76,91)$ & $56(47,65)$ & $57(49,66)$ & $88(79,94)$ & $89(81,95)$ & $55(46,63)$ \\
\hline
\end{tabular}

Values are percentages with $95 \% \mathrm{CI}$ in parentheses.

respectively. In the validation cohort, the sensitivities and specificities were similar but with narrower confidence intervals (table 6).

\section{Discussion}

We have demonstrated that $\mathrm{RM}\left(\mathrm{RM}_{1}\right.$ and $\left.\mathrm{RM}_{2}\right)$ as derived from parent-completed diary cards completed at 1 year corrected age was a better predictor of excess respiratory problems at 24 months corrected age than a diagnosis of BPD in extremely low gestational age infants. We undertook the initial analysis on a small subset of UKOS infants as we had very detailed information about them, including a 2-week diary card prior to pulmonary function testing (development cohort). Our subsequent analysis, on a larger subset whose parents also completed 4-week diary cards at 12 months corrected age (validation cohort), regardless of which BPD definition was used, demonstrated that RM was a significantly better predictor of respiratory outcomes at 24 months corrected age.

We compared $\mathrm{RM}_{1}$ and $\mathrm{RM}_{2}$ to two definitions of $\mathrm{BPD}$. Studies have defined BPD as an oxygen requirement at 28 days after birth or 36 weeks PMA. Shennan et al. [11] suggested that the need for oxygen supplementation at 36 weeks PMA, rather than 28 days after birth, was a more accurate predictor of longer-term outcome. The definition, however, did not correlate well specifically with long-term pulmonary outcome [11], whereas we had found in a subsequent study that the 28-day definition was a better predictor of long-term pulmonary outcome [12]. At an NIH consensus conference, the diagnosis of BPD was agreed to be made at 28 days and also included assignment of severity of BPD at 36 weeks PMA in prematurely born infants [13]. Nevertheless, when a cohort of premature infants was followed to 18-22 months corrected age, the NIH definition of BPD correctly predicted long-term RM only $35-40 \%$ of the time, although the accuracy increased as the severity of BPD worsened [14]. A further major limitation in using BPD as an outcome is that premature infants who do not develop BPD can also suffer from chronic respiratory problems.

The definitions of $\mathrm{RM}_{1}$ and $\mathrm{RM}_{2}$ were based on the results of a 2-week diary card, but we validated the analysis using results from a 4-week diary in a larger dataset. In that analysis, the infant was required to be symptomatic in any 2 weeks of a 4 -week period (not necessarily consecutive weeks). We again demonstrated that $\mathrm{RM}_{1}$ and $\mathrm{RM}_{2}$ were significant predictors of respiratory outcomes documented at 24 months corrected age. These results highlight that symptoms of cough and/or wheeze and requirement for respiratory medications are predictive of longer-term abnormal respiratory outcome. 
We decided a priori to assess a definition of RM as cough, wheeze, and/or medication use on 3 or more days each week for a 2 -week consecutive period. That definition was predictive, but our sensitivity analysis demonstrated that $\mathrm{RM}_{2}$ (at least 4 days of cough/wheeze/medication use per week for a 2-week consecutive period) tended to be a stronger predictor of respiratory outcome at 24 months corrected age. Those results suggest, not surprisingly, the more symptomatic the infant is, the more likely they will suffer an abnormal respiratory outcome. We did not, however, test this hypothesis further, as using a definition which involved even more days of cough/wheeze/medicine use, although likely to be more specific, would lose sensitivity.

Our study has some potential limitations. The data were prospectively collected to assess respiratory outcome in a high-risk population, but were retrospectively analysed. The infants had been entered into a randomised trial (UKOS) [7], but there were no significant differences in the short-term outcomes between the two groups, hence we pooled the data for the analysis. Data from only 76 infants (development cohort) were included in the initial analysis as they had had PFTs at 12 months corrected age, but they were representative of the entire UKOS population with regard to their demographics [8]. Hence, we feel these results are generalisable to larger populations of extremely low gestational age infants. At 24 months corrected age, parents completed respiratory questionnaires with their paediatrician who had the hospital records with them, so we feel the questionnaires reflected the respiratory outcomes of the infants. Indeed, comparison has shown a good correlation of parental reports with paediatrician records for hospital admissions, asthma, and bronchitis [15]. We undertook a subsequent analysis on a larger cohort of infants (validation cohort), and the results confirmed that $\mathrm{RM}_{1}$ and $\mathrm{RM}_{2}$ compared to $\mathrm{BPD}_{28 \mathrm{~d}}$ and $\mathrm{BPD}_{36 \mathrm{w}}$ were better predictors of respiratory outcome at 24 months corrected age.
In conclusion, we have demonstrated that RM diagnosed from a 2 -week parent-completed diary at 1 year corrected age better predicted abnormal respiratory outcomes at 24 months corrected age than BPD defined either as oxygen dependency at 28 days or 36 weeks PMA. $\mathrm{We}$, therefore, suggest that data from parent-completed diary cards at 1 year corrected age, rather than BPD, may be a better outcome measure when assessing the efficacy of interventions aimed at improving long-term respiratory outcome in extremely low gestational age infants.

\section{Acknowledgements}

\section{Funding Sources}

The research was funded/supported by the National Institute of Health (NH56398), National Center for Advancing Translational Sciences (UL1 TR000073), and the Eunice Kennedy Shriver National Institute of Child Health and Human Development (ULIRR025752-02). The research was funded/supported by the National Institute for Health Research (NIHR) Biomedical Research Centre based at Guy's and St. Thomas' NHS Foundation Trust and King's College London. The views expressed are those of the author(s) and not necessarily those of the NHS, the NIHR, or the Department of Health.

\section{Financial Disclosure}

N.M. and A.G. are NIHR Senior Investigators. A.G. is an MRC and Asthma UK Centre in Allergic Mechanisms of Asthma Investigator which is supported by an MRC Centre Grant (G1000758). J.L. was supported by the NIHR Biomedical Research Centre based at Guy's and St. Thomas' NHS Foundation Trusts and King's College London.

\section{Disclosure Statement}

A.G. has held grants from various ventilator manufacturers and has received honoraria for giving lectures and advising various ventilator manufacturers.

\section{References}

1 Greenough A: Long term respiratory outcomes of extreme prematurity $(<32$ weeks). Semin Fetal Neonatal Med 2012; 17:73-76.

2 Tyson JE, Wright LL, Oh W, Kennedy KA, Mele L, Ehrenkranz RA, Stoll BJ, Lemons JA, Stevenson DK, Bauer CR, Korones SB, Fanaroff AA: Vitamin A supplementation for extremely-low-birth-weight infants. National Institute of Child Health and Human Development Neonatal Research Network. N Engl J Med 1999;340:1962-1968.
3 Ambalavanan N, Tyson JE, Kennedy KA, Hansen NI, Vohr BR, Wright LL, Carlo WA; National Institute of Child Health and Human Development Neonatal Research Network: Vitamin A supplementation for extremely low birth weight infants: outcome at 18 to 22 months. Pediatrics 2005;115:e249-e254.

4 Davis JM, Parad R, Michele T, Allred E, Price A, Rosenfeld W; North American Recombinant Human CuZnSOD Study Group: Pulmonary outcome at 1 year corrected age in premature infants treated at birth with re- combinant human $\mathrm{CuZn}$ superoxide dismutase. Pediatrics 2003;111:469-476.

5 Greenough A, Giffin F, Yuksel B, Dimitriou G: Respiratory morbidity in young school children born prematurely - chronic lung disease is not a risk factor? Eur J Pediatr 1996; 155:823-826.

6 Broughton S, Thomas MR, Marston L, Calvert SA, Marlow N, Peacock JL, Rafferty GF, Greenough A: Very prematurely born infants wheezing at follow up: lung function and risk factors. Arch Dis Child 2007;92:776-780. 
7 Johnson AH, Peacock JL, Greenough A, Marlow N, Limb ES, Marston L, Calvert SA; United Kingdom Oscillation Study Group: High frequency oscillatory ventilation for the prevention of chronic lung disease of prematurity. New Engl J Med 2002;347:633-642.

8 Thomas MR, Rafferty GF, Limb ES, Peacock JL, Calvert SA, Marlow N, Milner AD, Greenough A: Pulmonary function at follow-up of very preterm infants from the United Kingdom Oscillation Study. Am J Respir Crit Care Med 2004;169:868-872.

9 Marlow N, Greenough A, Peacock JL, Marston L, Limb ES, Johnson AH, Calvert SA: Randomised trial of high frequency oscillatory ventilation or conventional ventilation in babies of gestational age 28 weeks or less: respiratory and neurological outcomes at 2 years. Arch Dis Child Fetal Neonatal Ed 2006;91:F320-F326.

10 Hanley JA, McNeil BI: A method of comparing the areas under receiver operating characteristic curves derived from the same case. Radiol 1983; 148:839-843.

11 Shennan AT, Dunn MS, Ohlsson A, Lennox $\mathrm{K}$, Hoskins EM: Abnormal pulmonary outcomes in premature infants: prediction from oxygen requirement in the neonatal period. Pediatrics 1988;82:527-532.

12 Kinali M, Greenough A, Dimitriou G, Yuksel B, Hooper R: Chronic respiratory morbidity following premature delivery - prediction by prolonged respiratory support requirement. Eur J Pediatr 1999;158:493-496.

13 Jobe A, Bancalari E: Bronchopulmonary dysplasia. Am J Respir Crit Care Med 2001;163: 1723-1729.

14 Ehrenkranz R, Walsh M, Vohr B, Jobe AH, Wright LL, Fanaroff AA, Wrage LA, Poole K; National Institutes of Child Health and $\mathrm{Hu}-$ man Development Neonatal Research Network: Validation of the National Institutes of Health consensus definition of bronchopulmonary dysplasia. Pediatrics 2005;116:13531360.

15 Pless CE, Pless IB: How well they remember. The accuracy of parental reports. Arch Pediatr Adolesc Med 1995;149:553-558. 